\title{
Voltage-Gated Sodium Channels Regulating Action Potential Generation in Itch-, Nociceptive-, and Low-Threshold Mechanosensitive Cutaneous C-Fibers
}

\author{
Danica Jurcakova, Fei Ru, Marian Kollarik, Hui Sun, Jeffrey Krajewski, \\ and Bradley J. Undem

\begin{abstract}
Department of Medicine, School of Medicine, Johns Hopkins University, Baltimore, Maryland (D.J., F.R., M.K., H.S., B.J.U,); Biomedical Center and Department of Pathophysiology, Jessenius Faculty of Medicine, Comenius University in Bratislava,
\end{abstract} \\ Martin, Slovakia (D.J., M.K.); and Lilly Research Laboratories, Indianapolis, Indiana (J.K.)
}

Received May 1, 2018; accepted June 20, 2018

\begin{abstract}
We evaluated the effect of voltage-gated sodium channel $1\left(\mathrm{Na}_{\mathrm{V}} 1\right)$ blockers in three nonoverlapping $\mathrm{C}$-fiber subtypes in the mouse skin: chloroquine (CQ)-sensitive C-fibers with high mechanical thresholds-itch C-fibers; second, CQ-insensitive, capsaicin-sensitive C-fibers with high mechanical thresholdsnociceptors; and CQ and capsaicin-insensitive C-fibers with a very low mechanical threshold-C-LTMs. Na 1 1-blocking drugs were applied to the nerve terminal receptive fields using an innervated isolated dorsal mouse skin-nerve preparation where the drugs are delivered into the skin intra-arterially. We combined these studies with an analysis of the mRNA expression of the $\alpha$-subunits of $\mathrm{Na}_{v} 1$ in individual dorsal root ganglia neurons labeled from the same region of the skin. Our results show that
\end{abstract}

virtually all nociceptors and itch $\mathrm{C}$-fibers expressed the tetrodotoxin (TTX)-resistant channels $\mathrm{Na}_{\mathrm{V}} 1.8$ and $\mathrm{Na}_{\mathrm{v}}$ 1.9. However, TTX applied selectively into the skin abolished the action potential firing in response to mechanical stimulation in $75 \%$ of the itch C-fibers, $100 \%$ of the nociceptors, and $100 \%$ of C-LTMs. Nav1.7 was the most commonly expressed TTX-sensitive $\mathrm{Na}_{v} 1$ in all three C-fiber subtypes innervating the dorsal skin. Selectively blocking $\mathrm{Na}_{\mathrm{v}} 1.7$ abolished responses in about $40 \%$ of itch C-fibers, $65 \%$ of nociceptors, but only $20 \%$ of C-LTMs. Blocking $\mathrm{Na}_{\mathrm{v}} 1.8$ alone had no affect on the firing sensitivity of the $\mathrm{C}$-fibers. However, in itch and nociceptive $\mathrm{C}$-fibers where the activation was not inhibited with a Nav1.7 blocker, adding the Nav1.8 blocker silenced action potential discharge.

\section{Introduction}

The majority of electrophysiological studies on cutaneous C-fibers in laboratory animals have been focused on nerve fibers terminating in the glabrous and nonglabrous aspect of the hind paw. Electrophysiological recordings from cutaneous sensory nerves reveal subpopulations of C-fibers based on their stimulus profile. Accordingly, there are C-fibers that are unresponsive to mechanical stimulation, those that respond to mechanical stimuli with low and high thresholds, and those that respond to heat, cold, chemical, inflammatory mediators, or some combination thereof (Kress et al., 1992; Lawson et al., 2008; Dubin and Patapoutian, 2010).

We recently developed a skin-nerve preparation ideally suitable for investigating the pharmacology of C-fibers

This work was partially supported by the Department of Education, Slovakia [Grants APVV-15-0163 and VEGA 1/0306/18] (to D.J.).

https://doi.org/10.1124/mol.118.112839. terminating in the skin covering the dorsal thorax. Using this technique we noted that essentially all C-fibers terminating in this region of the skin are mechanically sensitive, and the vast majority can be stimulated by capsaicin (and presumably therefore also heat) (Ru et al., 2017). Based on their chemical sensitivity profile, the C-fibers can be further subdivided into presumed itch (scratch evoking) C-fibers and nociceptive C-fibers (Liu et al., 2009; Han et al., 2013; Ru et al., 2017). In this study we further analyzed the mechanical and chemical sensitivity of the C-fiber subtypes innervating the dorsal thorax of the mouse.

Regardless of the stimulus, the information from the C-fiber terminal will not reach the central nervous system without the activation of voltage-gated sodium channel $1\left(\mathrm{Na}_{V} 1\right)$ channels during the generation and conduction of an action potential (AP). Among the nine pore-forming $\alpha$-subunits of $\mathrm{Na}_{\mathrm{V}} 1$ channels $\left(\mathrm{Na}_{\mathrm{V}} 1.1\right.$ to $\left.\mathrm{Na}_{\mathrm{V}} 1.9\right)$, all but $\mathrm{Na}_{\mathrm{V}} 1.5$ (cardiac) and $\mathrm{Na}_{\mathrm{V}} 1.4$ (striated muscle) are commonly expressed in neurons.

ABBREVIATIONS: 5-HT, 5-hydroxytryptamine (serotonin); A803467, 5-(4-chlorophenyl)- $N$-(3,5-dimethoxyphenyl)furan-2-carboxamide; AP, action potential; BAM8-22, H-Val-Gly-Arg-Pro-Glu-Trp-Trp-Met-Asp-Tyr-Gln-Lys-Arg-Tyr-Gly-OH; C-HTMs, high-threshold mechanosensitive C-fibers; C-LTMs, low-threshold mechanosensitive C-fibers; compound 13, 4-[2-(1-Azetidin-3-yl-1H-pyrazol-5-yl)-5-chloro-2-fluoro-4-(trifluoromethyl)phenoxy]-N-1,3,4-thiadiazol-5-ylbenzenesulfonamide; CQ, chloroquine; Dil, 1,1'-dioctadecyl-3,3,3',3'-tetramethylindocarbocyanine perchlorate; DRG, doral root ganglia; ICA-121431, 2,2-diphenyl- $N$-[4-(1,3-thiazol-2-ylsulfamoyl)phenyl]acetamide; MRGPRA3, Mas-related G-protein coupled receptor member A3; $\alpha, \beta$-meATP, $\alpha, \beta$-methylene ATP; Nav1, voltage-gated sodium channel 1; PCR, polymerase chain reaction; PF-05089771, 4-[2(5-amino-1H-pyrazol-4-yl)-4-chlorophenoxy]-5-chloro-2-fluoro- $N$-(1,3-thiazol-4-yl)benzenesulfonamide; RT-PCR, reverse-transcription polymerase chain reaction; TRPV1, transient receptor potential cation channel subfamily $\mathrm{V}$ member 1 ; TTX, tetrodotoxin. 
Tetrodotoxin (TTX), a frequently used toxin to study $\mathrm{Na}_{\mathrm{V}} 1$ function, potently and selectively blocks $\mathrm{Na}_{\mathrm{v}} 1.1,1.2,1.3,1.4$, 1.6, and 1.7, but has little effect on $\mathrm{Na}_{\mathrm{V}} 1.5,1.8$, and 1.9. The specific $\mathrm{Na}_{\mathrm{V}} 1$ subtypes expressed in a nerve depend on the neuronal phenotype (Lai et al., 2004).

Complicating matters is the observation that the nature of the $\mathrm{Na}_{\mathrm{V}} 1$ controlling APs may not be constant along different aspects of the nerve. For example, AP generation at the terminals of C-fibers in the cornea does not require TTX-sensitive $\mathrm{Na}_{V} 1$ channels, but the conduction of the AP along the trigeminal axons toward the cell bodies in the trigeminal ganglion is abolished by TTX (Brock et al., 1998). Likewise, selectively blocking $\mathrm{Na}_{\mathrm{V}} 1.7$ can prevent conduction of APs in vagal afferent A- and C-fibers (Muroi et al., 2011; Kollarik et al., 2018). In contrast, blocking $\mathrm{Na}_{\mathrm{V}} 1.7$ (and other TTX-sensitive channels) at the terminals of a subset of vagal $\mathrm{C}$-fibers within the trachea or lungs is without effect on chemical-induced initiation of action potentials, where $\mathrm{Na}_{\mathrm{V}} 1.8$ appears to play a more important role (Kollarik et al., 2018). The same holds in spinal afferent nerves of mice and nonhuman primates where conduction of APs in afferent axons close to the peripheral tissue of their innervation is more TTX-resistant than conduction along more central aspects of the nerve (Klein et al., 2017).

Description of the characteristics of the $\mathrm{Na}_{\mathrm{V}} \mathrm{ls}$ involved in $\mathrm{AP}$ generation has benefited greatly from genetic deletion studies; however, this strategy eliminates the $\mathrm{Na}_{\mathrm{v}}$ channel from all aspects of the nerve. In the present study, we determined the $\mathrm{Na}_{\mathrm{V}} 1$ subtypes involved in AP formation in C-fiber subtypes specifically within the cutaneous compartment-the aspect of the nerve that would be effectively influenced by topically applied $\mathrm{Na}_{\mathrm{V}}$-blocking drugs. This was performed by taking advantage of $\mathrm{Na}_{\mathrm{v}} 1$ subtype-selective blockers combined with an ex vivo skinnerve preparation that allows for the delivery of drugs directly to the nerve's receptive field in the skin via intra-arterial injections.

\section{Materials and Methods}

Animals. The animals used in the experiments were male mice C57BL/6J, 6 to 8 weeks old, weighing $22-27 \mathrm{~g}$. The mice were housed with a 12 -hour light/dark cycle at air temperature $22^{\circ} \mathrm{C}$, with access to water and food ad libitum. All experiments were approved by the Johns Hopkins Animal Use and Care Committee.

Retrograde Labeling of Cutaneous Nerve Fibers. The mice were anesthetized with $50 \mathrm{mg} / \mathrm{kg}$ of ketamine and $10 \mathrm{mg} / \mathrm{kg}$ of xylazine dissolved in physiologic saline. The hair on dorsal skin (Fig. 1) was shaved using an electrical razor. The exposed skin was labeled with retrograde tracer 1,1'-dioctadecyl-3,3,3',3'-tetramethylindocarbocyanine perchlorate (Dil, $0.1 \%$ in $10 \%$ dimethylsulfoxide:saline mixture) up to a total volume of $200 \mu \mathrm{l}$ (applied directly on the skin surface). After 14 days, the dorsal root ganglia (DRG) from treated mice were dissociated and used for cell picking.

DRG Dissociation. We followed the protocol described in detail elsewhere (Kwong et al., 2008; Ru et al., 2011; Surdenikova et al., 2012; Kocmalova et al., 2017). Briefly, mice DRG (T8-T10) were dissected and dissociated by trituration and enzymatic treatment $(2 \mathrm{mg} / \mathrm{ml}$ of collagenase type 1A; $2 \mathrm{mg} / \mathrm{ml}$ of Dispase II in $\mathrm{Ca}^{2+}-, \mathrm{Mg}^{2+}$-free Hanks' balanced salt solution), were plated on poly-D-lysine and laminin-coated coverslips, and were incubated 2 hours at $37^{\circ} \mathrm{C}$. The coverslips were flooded with $2 \mathrm{ml}$ of L-15 medium supplemented with $10 \%$ fetal bovine serum and used within 8 hours (for cell picking) or within 24 hours (for patch clamp recording).

Patch Clamp Recording. The conventional whole-cell patch clamp technique was employed to record the sodium current $\left(\mathrm{I}_{\mathrm{Na}}\right)$ using an Axopatch 200B amplifier (Axon Instruments/Molecular Devices, Sunnyvale, CA) interfaced with Axon Digidata 1550A (Axon Instruments) and driven by pCLAMP 10 software (Molecular Devices, Sunnyvale, CA). The bath solution contained ( $\mathrm{mM}$ ) choline-Cl 126, $\mathrm{NaCl} 10, \mathrm{CsCl} 3$, TEA-Cl 5, $\mathrm{MgCl} 21, \mathrm{CaCl}_{2} 1, \mathrm{CdCl}_{2}$ 0.1, HEPES 10, and glucose 10 , with the $\mathrm{pH}$ adjusted to 7.35 with $\mathrm{CsOH}$. The pipette solution contained (mM): $\mathrm{CsF} 140, \mathrm{NaCl} 10, \mathrm{MgCl}_{2} 1, \mathrm{CaCl}_{2} 0.1$, EGTA 1.1, and HEPES 10, with the $\mathrm{pH}$ adjusted to 7.2 with $\mathrm{CsOH}$. Cell capacitance and series resistance were compensated electronically by $\sim 80 \%$ to ensure an adequate voltage control. To record $\mathrm{I}_{\mathrm{Na}}$, the cells were held at $-110 \mathrm{mV}$, and two depolarizing pulses, separated by a 1-second interval at $-60 \mathrm{mV}$, were applied every 5 seconds to voltages ranging from -90 to $+20 \mathrm{mV}$ at an increment of $5 \mathrm{mV}$. The second pulse was used to record the TTX-resistant $\mathrm{I}_{\mathrm{Na}}$. The current was sampled at $50 \mathrm{kHz}$ and filtered at $10 \mathrm{kHz}$.

Cell Picking. Coverslips with dissociated neurons were perfused with phosphate-buffered saline and Dil-labeled neurons were identified under a fluorescent microscope. Neurons free of debris or attached
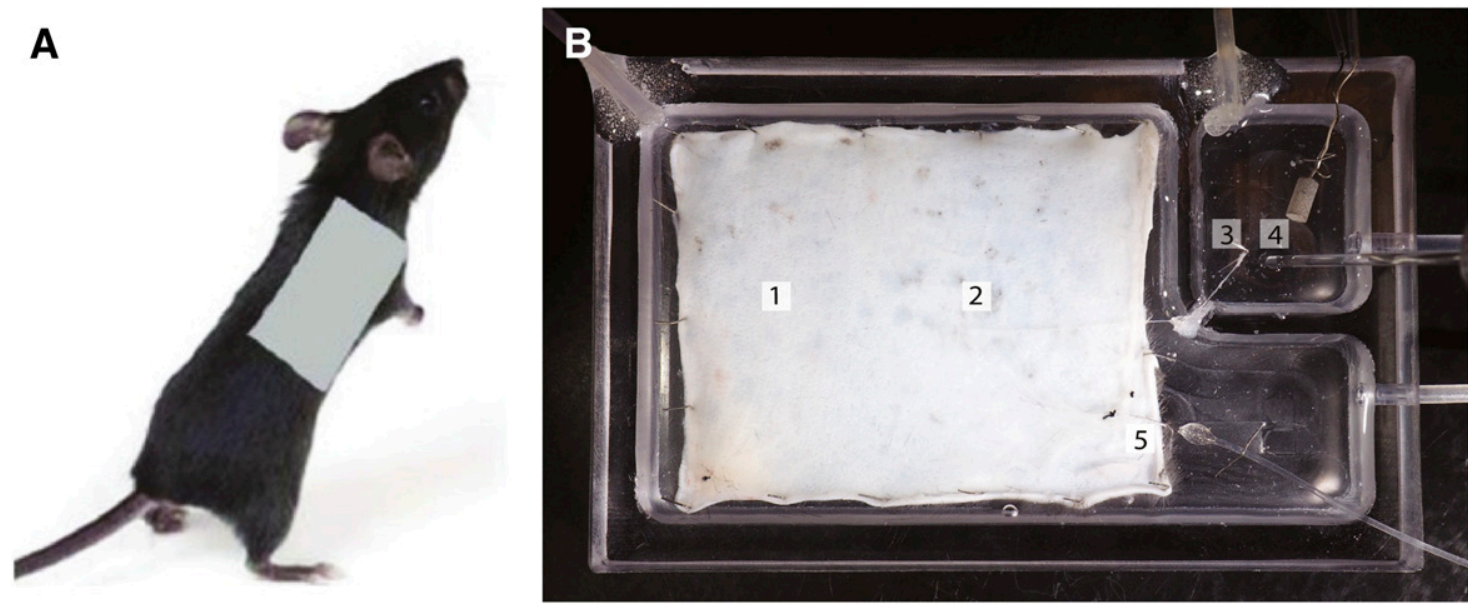

Fig. 1. Mouse skin-nerve ex vivo preparation. (A) Location of skin used for retrograde labeling and electrophysiologic recordings. (B) The dorsal root ganglia (DRG)/spinal nerve-skin preparation. The skin (1) is pinned dermis side up in the tissue chamber, the T9 thoracic nerve (2) passes through a hole sealed with Vaseline into the recording chamber where the T9 DRG (3) is positioned and pinned at the distal end. An extracellular recording electrode (4) has the tip positioned in the dorsal root ganglia. The tissue and the recording chamber are separately superfused with warm Krebs solution. Mechanical stimuli (von Frey hairs) are applied to the dermis (corium) side of the skin. Chemicals are delivered via cannulated right subscapular artery (5) connected to polyethylene tubing (edited from Ru et al., 2017). 
cells were harvested individually into a glass-pipette by applying negative pressure. The pipette tip containing the cell was broken into a polymerase chain reaction (PCR) tube containing RNAse Inhibitor ( $1 \mu$ l, RNAseOUT, 2 U L-1; Invitrogen, Carlsbad, CA), immediately frozen and stored at $-20^{\circ} \mathrm{C}$. From every coverslip a sample of the bath solution was collected for no-template experiments (bath control).

Single-Cell Reverse-Transcription PCR. Single-cell reversetranscription PCR (RT-PCR) was performed as described elsewhere (Liu et al., 2009; Brozmanova et al., 2016). Briefly, samples with harvested cells were defrosted and reverse transcription was performed using Super-Script III CellsDirect cDNA Synthesis System (Invitrogen) according to the manufacturer's recommendations. A total of $2 \mu \mathrm{l}$ of cDNA or negative control was used for PCR, performed with HotStar Taq Poymerase Kit (Qiagen, Valencia, CA) in a final volume of $20 \mu \mathrm{l}$. Intron-spanning primers (Table 1) were designed based on PubMed sequences and Primer3 (Rozen and Skaletsky, 2000) and some published previously (Kocmalova et al., 2017). PCR products were visualized in a $1.5 \%$ agarose gel containing ethidium-bromide using QuantityOne software (Bio-Rad Laboratories, Hercules, CA).

Ex Vivo DRG Nerve-Skin Preparation. DRG-spinal nerve-skin preparation, which has been described in detail elsewhere ( $\mathrm{Ru}$ et al., 2017), is pictured in Fig. 1. Briefly, right dorsal mouse skin $(3 \times 3 \mathrm{~cm})$ with the main arterial supply (subscapular artery) was dissected along with spinal nerves and DRG (most often T9 or T8, occasionally $\mathrm{T} 7$ or T10). If present, the vessels other than the subscapular artery were ligated to prevent a rapid exit of chemicals infused into subscapular artery. The skin was pinned dermis side up in a Sylgard-lined Perspex tissue chamber, the DRG ganglion with the nerve was positioned in adjacent Sylgard-lined recording chamber.

The tissue and recording chamber were separately superfused with Krebs solution at a flow rate of 4 (temperature $32-34^{\circ} \mathrm{C}$ ) and $3 \mathrm{ml} \min ^{-1}\left(36-37^{\circ} \mathrm{C}\right)$, respectively. Krebs solution contained indomethacin $(3 \mu \mathrm{M})$ to overcome undesired C-fiber sensitization due to prostanoid release resulting from mechanical probing the skin over time (Emery et al., 2016).

Extracellular Recording of DRG Fibers in the Skin. The method for the extracellular recording from the dorsal root neurons projecting to the skin has been described in detail in Ru et al. (2017). The aluminosilicate glass electrode filled with $3 \mathrm{M} \mathrm{NaCl}$ was manipulated into the DRG in the recording chamber where a return electrode of silver-silver chloride wire and an earthed silver-silver chloride pellet were situated. The recording signal was amplified (Microelectrode AC amplifier 1800; A-M Systems, Sequim, WA) and

TABLE 1

Primer sequences for single-cell reverse-transcription polymerase chain reaction

\begin{tabular}{|c|c|c|c|}
\hline Gene & Primer & Sequence $\left(5^{\prime}\right.$ to $\left.3^{\prime}\right)$ & $\begin{array}{l}\text { Product Size } \\
\text { (bp) }\end{array}$ \\
\hline \multirow[t]{2}{*}{$\beta$-Actin } & Forward & GTGGGAATGGGTCAGAAGG & 302 \\
\hline & Reverse & GAGGCATACAGGGACAGCA & \\
\hline \multirow[t]{2}{*}{ MRGPRA3 } & Forward & CGACAATGACACCCACAACAA & 150 \\
\hline & Reverse & GGAAGCCAAGGAGCCAGAAC & \\
\hline \multirow[t]{2}{*}{ TRPV1 } & Forward & GCTGCTAACGGGGACTTCTT & 285 \\
\hline & Reverse & CTTCAGTGTGGGGTGGAGTT & \\
\hline \multirow[t]{2}{*}{$\mathrm{Na}_{\mathrm{V}} 1.1$} & Forward & AGACAGCATCAGGAGGAAGG & 118 \\
\hline & Reverse & GGAGAACAGGGAACCACGA & \\
\hline \multirow[t]{2}{*}{$\mathrm{Na}_{\mathrm{V}} 1.2$} & Forward & CATTTTCGGCTCATTCTTCA & 305 \\
\hline & Reverse & CATCTCTTGGCTCTGGTCGT & \\
\hline \multirow{2}{*}{$\mathrm{Na}_{\mathrm{V}} 1.3$} & Forward & AGACAGAGGGAGCACTTGGA & 200 \\
\hline & Reverse & CTATTGCGTCTTGGGGAAAA & \\
\hline \multirow[t]{2}{*}{$\mathrm{Na}_{\mathrm{V}} 1.6$} & Forward & AGGCAGCAAAGACAAACTGG & 157 \\
\hline & Reverse & GCAGCACTTGAACCTCTGG & \\
\hline \multirow[t]{2}{*}{$\mathrm{Na}_{\mathrm{V}} 1.7$} & Forward & ATGCTCTTCTTTGCGGTTTC & 381 \\
\hline & Reverse & CCTGCTCTTTTCGGCTTCTT & \\
\hline \multirow[t]{2}{*}{$\mathrm{Na}_{\mathrm{V}} 1.8$} & Forward & CAATCCGACCCTTACAACCA & 147 \\
\hline & Reverse & AAAGACCCCGTCATCCAAG & \\
\hline \multirow[t]{2}{*}{$\mathrm{Na}_{\mathrm{V}} 1.9$} & Forward & CAGCTTTGGCTGGTCTTTTC & 228 \\
\hline & Reverse & TTCTCCTTGGCCTCTGTCTC & \\
\hline
\end{tabular}

filtered (low cutoff $0.3 \mathrm{kHz}$; high cutoff $1 \mathrm{kHz}$ ), and the resultant activity was displayed on an oscilloscope (TDS 3054B; Tektronix, Beaverton, OR) connected to an Apple computer.

The receptive fields of skin afferent nerves was searched with a small concentric electrically stimulating electrode. Once the electrical receptive field of a single nerve fiber was obtained and the conduction velocity was calculated, the field was probed for mechanical sensitivity using a punctuate mechanical stimulus (von Frey hair). Then the chemical sensitivity was determined.

All chemicals were diluted in Krebs solution and applied via intraarterial infusion into subscapular artery at a rate of $50 \mu \mathrm{l} / \mathrm{s}$ in a total volume of $200 \mu \mathrm{l}$. For every nerve studied, the vehicle was applied to ensure there was no artifactual response due to any change in mechanical force resulting from the injection. Antagonists were superfused over the tissue for 30 minutes and were delivered to the receptive field intra-arterially at the rate $50 \mu \mathrm{l} / \mathrm{min}$.

Merely superfusing the $\mathrm{Na}_{\mathrm{v}} 1$-blocking drugs (at the concentration used in this study) did not block AP conduction to the DRG, likely due to the barrier provided by the skin and the perineural sheath protecting the axons. Therefore, the small amount of drug that left the skin tissue into the superfusing solution is unlikely to have influenced the results.

Mouse Trachea. We used the isolated mouse trachea to determine the selectivity and the potency of PF-05089771 (4-[2-(5-amino- $1 H$ pyrazol-4-yl)-4-chlorophenoxy]-5-chloro-2-fluoro- $N$-(1,3-thiazol-4-yl)benzenesulfonamide) on $\mathrm{Na}_{\mathrm{V}} 1$.7-dependent nerve-evoked cholinergic contractions (Kocmalova et al., 2017). The methods used were exactly as we described elsewhere (Weigand et al., 2009).

The neuronal responses in this isolated mouse tissue preparation are inhibited only when both $\mathrm{Na}_{\mathrm{V}} 1.7$ and $\mathrm{Na}_{\mathrm{V}} 1.1$ (and maybe 1.3) are blocked. In seven experiments PF-05089771, studied in the presence of ICA121431 (2,2-diphenyl- $N$-[4-(1,3-thiazol-2-ylsulfamoyl)phenyl]acetamide) to block $\mathrm{Na}_{\mathrm{V}} 1.1$ and 1.3 , antagonized the $\mathrm{Na}_{\mathrm{V}} 1.7$ responses in the isolated tracheal tissue with about the same potency as we found for compound 13 ( $\mathrm{IC}_{50}$ of $\sim 300 \mathrm{nM}$ ), and a maximal (>90\%) block at $10 \mu \mathrm{M}$. At $10 \mu \mathrm{M}$ neither PF-05089771 alone, nor compound 13 , nor A803467 [5-(4-chlorophenyl)- $N$-(3,5-dimethoxyphenyl)furan2-carboxamide] had any effect on the neuronally evoked cholinergic contractions.

Drugs and Chemicals. If not stated otherwise all drugs were purchased from Sigma-Aldrich (St. Louis, MO). Chloroquine (CQ), histamine, $\alpha, \beta$-methylene ATP ( $\alpha, \beta$-meATP), 5-hydroxytryptamine (serotonin) (5-HT), BAM8-22 (H-Val-Gly-Arg-Pro-Glu-Trp-Trp-MetAsp-Tyr-Gln-Lys-Arg-Tyr-Gly-OH; GenScript, Piscataway, NJ), TTX (Alamone Laboratories, Jerusalem, Israel) were dissolved in distilled water. Capsaicin and indomethacin were dissolved in ethanol. ICA121431, PF-05089771, and A803467 (all Tocris, Minneapolis, MN) and compound 13 (4-[2-(1-Azetidin-3-yl-1H-pyrazol-5-yl)-5-chloro-2fluoro-4-(trifluoromethyl)phenoxy]-N-1,3,4-thiadiazol-5-ylbenzenesulfonamide; first described in Markworth et al., 2011; Almirall Laboratories, Barcelona, Spain; see figure in (Kocmalova et al., 2017)) were dissolved in dimethylsulfoxide. TTX and indomethacin were prepared as a 1 and $30 \mathrm{mM}$ stock solutions, respectively; all other compounds were prepared as $10 \mathrm{mM}$ stock solutions before being diluted in Krebs solution to their final concentrations on the day of use: 5-HT $(10 \mu \mathrm{M}), \mathrm{A} 803467(30 \mu \mathrm{M})$, capsaicin $(1 \mu \mathrm{M})$, compound $13(3 \mu \mathrm{M}), \mathrm{CQ}(100 \mu \mathrm{M})$, histamine $(100 \mu \mathrm{M}), \mathrm{ICA}-121431(10 \mu \mathrm{M})$, indomethacin $(3 \mu \mathrm{M})$, PF-05089771 (3 $\mu \mathrm{M})$, TTX $(1 \mu \mathrm{M})$, and $\alpha, \beta$-meATP $(10 \mu \mathrm{M})$.

Experimental Design and Statistical Analysis. The data are presented as mean \pm S.E.M. The response of fibers to mechanical stimulus was quantified as peak frequency-the largest number of action potentials in any $1 \mathrm{~s}$ bin-using the software TheNerveOfIt (PHOCIS, Baltimore, MD). One-way analysis of variance followed by Tukey's correction was used to compare quantified properties of fibers in a nonpaired fashion using GraphPad Prism 7 (GraphPad Software, San Diego, CA). $P<0.05$ was considered statistically significant. 


\section{Results}

Chemical and Mechanical Responsiveness of C-Fibers in the Skin. We focused this study on afferent nerve fibers that terminate in the dorsal skin and conducted action potentials at $<1 \mathrm{~m} / \mathrm{s}$-that is, the C-fibers. We studied $158 \mathrm{C}$-fibers, generally one fiber per mouse. All C-fibers found with our electrical search protocol could be activated with von Frey application to the receptive field in the skin. There is an impressive diffusion barrier to application of chemicals delivered via tissue superfusion to the receptive fields of C-fibers within the isolated dorsal skin of the mouse. We previously noted how this barrier can be circumvented by intra-arterial injection of chemicals, subsequent to cannulating the major vascular supply to the studied region of the isolated skin (Ru et al., 2017). This ex vivo approach offers the advantage of evaluating the activity of direct-acting chemicals but will likely underestimate the effects of those stimuli that act indirectly, such as via inflammatory responses, vasodilation, and plasma extravasation.

Based on the mechanical sensitivities there were two clear C-fiber subsets. One subset was exquisitely sensitive to mechanical stimulation; the force to cause 50\% maximal AP discharge $\left(\mathrm{EF}_{50}\right)$ averaged $3.8 \pm 0.7 \mathrm{mN}$ (Fig. 2A). These lowthreshold mechanically sensitive C-fibers (C-LTMs) did not respond to any chemical stimulant that we assessed: capsaicin, CQ, 5-HT, histamine, $\alpha, \beta$-meATP, or BAM8-22. The
C-LTMs comprised $20 \%$ of the total C-fiber population (Fig. 2B). The rest of the C-fibers responded to von Frey stimulation with a much ( $\sim 5$ times) higher threshold (C-HTMs) than C-LTMs (Fig. 2A). Each of the C-HTMs responded to at least one chemical stimulant assessed in this study.

We divided the C-HTMs into CQ-sensitive $\left(\mathrm{CQ}^{+}\right)$and $\mathrm{CQ}$-insensitive $\left(\mathrm{CQ}^{-}\right)$subsets. We have previously reported that $\mathrm{CQ}$ activation of $\mathrm{C}$-fiber in the skin and CQ-induced scratching depend on Mas-related G-protein coupled receptor member A3 (MRGPRA3) (Liu et al., 2009; Ru et al., 2017). In agreement with our previous data (Ru et al., 2017), we found that $24 \%$ of the C-fibers were CQ sensitive (Fig. 2B). Also in agreement with previous studies (Ru et al., 2017), nearly all (96\%) of $\mathrm{CQ}^{+}$fibers responded with AP discharge to BAM8-22 $(n=27)$, and $81 \%$ responded to histamine $(n=16)$ (Fig. 3 ). These fibers rarely responded to 5-HT (only 4 out of 29 fibers responded) or $\alpha, \beta$-meATP (3 out of 24 responded) (Fig. 3 ). In contrast, the vast majority of $\mathrm{CQ}^{-} \mathrm{C}$-fibers responded to 5 -HT (76\%, $n=99$ ) and $\alpha, \beta$-meATP $(85 \%, n=45)$, but these nerves were only rarely activated by BAM8-22 ( 2 out of 53 responded) or histamine (3 out of 25 responded) (Fig. 3).

The relative proportion of the three nonoverlapping phenotypes of C-fiber: $\mathrm{CQ}^{+}, \mathrm{CQ}^{-}$, and C-LTMs is illustrated in Fig. $2 \mathrm{~B}$. We did not routinely investigate capsaicin in this study, as this compound often leads to profound desensitization of the nerve, but in our previous study we found that the majority of
A

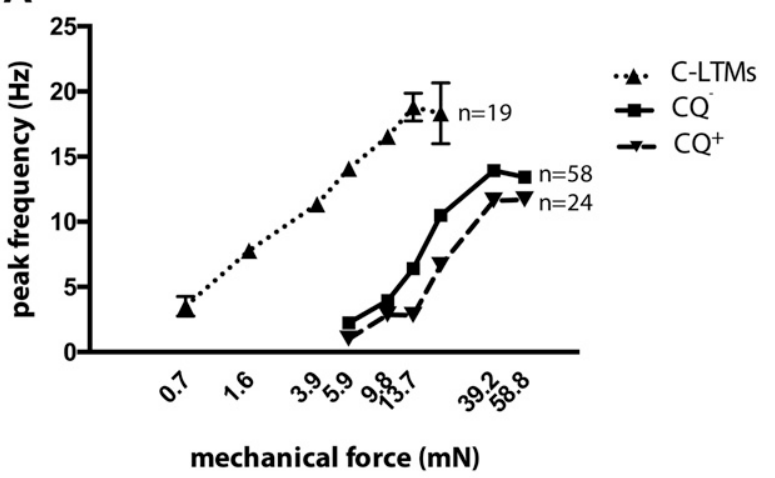

B
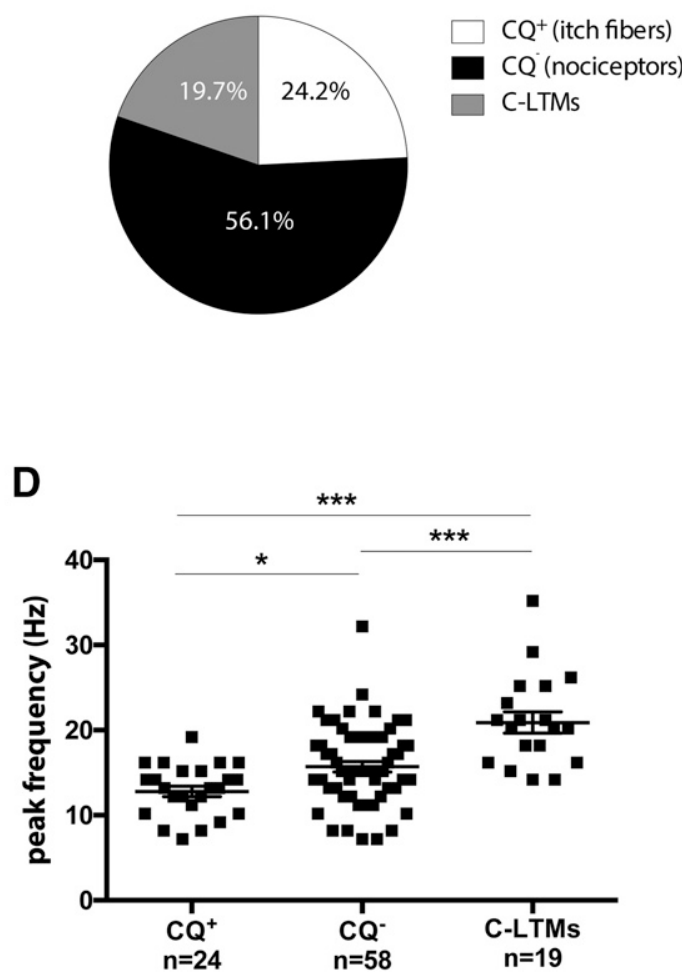

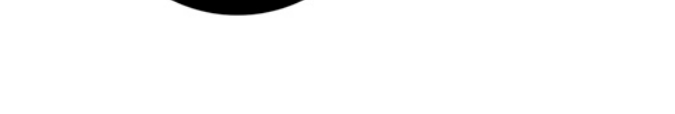

C

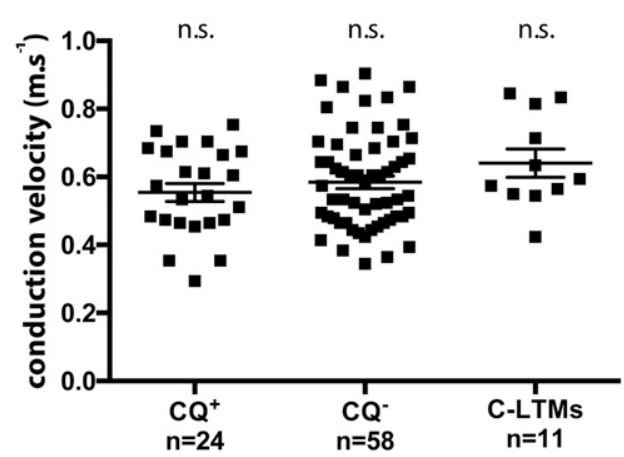

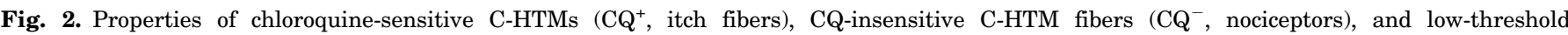

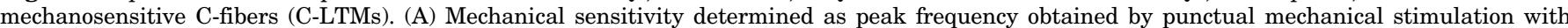

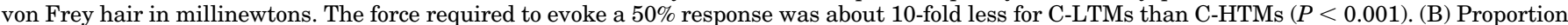

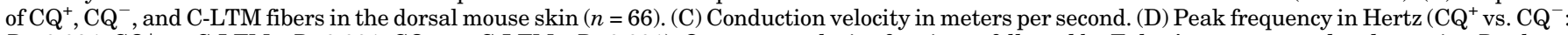

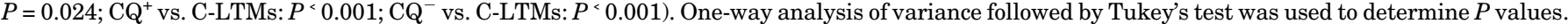
In $\mathrm{A}, \mathrm{C}$, and $\mathrm{D}$, the data are presented as mean \pm S.E.M. of individual fibers studied. 

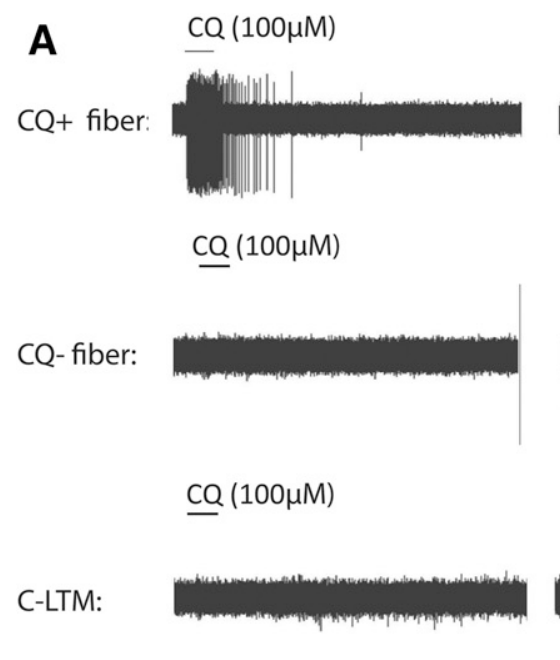
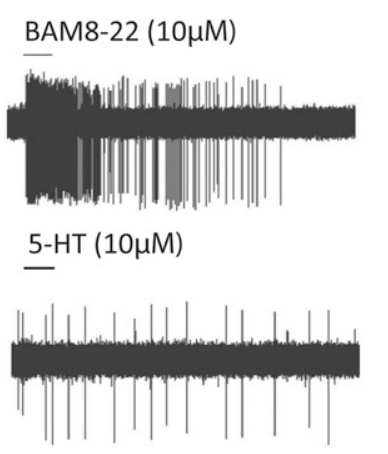

BAM8-22 (10 $\mu \mathrm{M})$

in

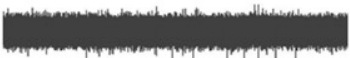

$\alpha, \beta$-meATP $(10 \mu \mathrm{M})$

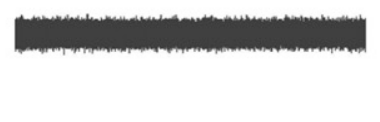

$\alpha, \beta$-meATP $(10 \mu \mathrm{M})$

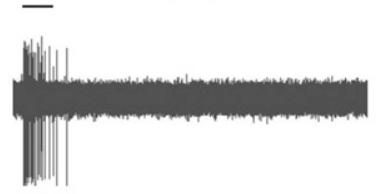

$\underline{\alpha, \beta}$-meATP $(10 \mu \mathrm{M})$

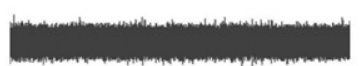

$10 \mathrm{~s}$

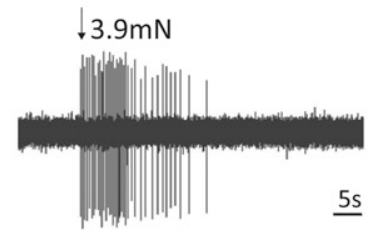

B

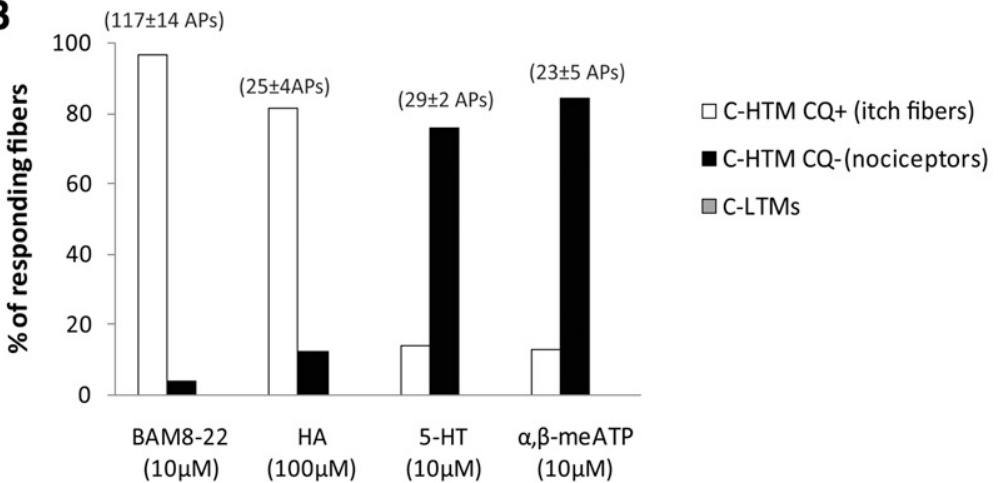

Fig. 3. Chemical responsiveness of C-fibers innervating the mouse skin. (A) Representative traces showing the action potential discharge evoked in response to chemical or mechanical stimulation. (B) The proportion of the three subtypes of C-fibers studied that respond to various chemicals. $\square$ C-HTMs that respond to CQ (itch fibers); C-HTM fibers that do not respond to CQ (nociceptors); and $\mathbb{\text { C }}$-LTMs. Among the chloroquine-sensitive (CQ ${ }^{+}$, itch) C-fibers (open bars), 26 of 27 responded to BAM8-22, 13 of 16 responded to histamine (HA), but only 4 of 29 to 5 -HT and 3 of 24 to $\alpha, \beta$-methylene ATP $\left(\alpha, \beta\right.$-meATP). On the other hand, CQ-insensitive high-mechanical-threshold C-fibers ( $\mathrm{CQ}^{-}$, nociceptors) (closed bars) responded to $\alpha, \beta$-meATP (38 of 45 fibers tested) and 5-HT (75 of 99 fibers tested) and only rarely to histamine ( 3 of 25) or BAM8-22 (2 of 53). Note: None of the low-threshold mechanosensitive C-fibers (C-LTMs) responded to any of assessed chemical stimuli $(n=14)$. Response to chemical stimuli is denoted above the columns as number of action potentials (AP) in mean \pm S.E.M.

C-fibers respond with action potential discharge to $1 \mu \mathrm{M}$ capsaicin (Ru et al., 2017). This is in agreement with the percentage of neurons expressing transient receptor potential cation channel subfamily V member 1 (TRPV1) in the singleneuron RT-PCR data we discuss later where $\sim 70 \%$ of all neurons labeled from dorsal skin expressed TRPV1.

Interestingly, the C-LTMs did not respond to capsaicin $(n=$ 4 of 4), indicating that some of the TRPV1-negative neurons comprise C-LTMs. We infer from the stimulation profile and current knowledge (Liu et al., 2009; Han et al., 2013; Ru et al., 2017), that $\mathrm{CQ}^{+} \mathrm{C}$-fibers in the skin represent itch (scratchevoking) C-fibers, whereas cutaneous capsaicin-sensitive $\mathrm{CQ}^{-}$ C-fibers comprise pain-evoking nociceptors, and C-LTMs transduce nonpainful tactile signals (Vallbo et al., 1999; Olausson et al., 2002). C-LTMs may also contribute to pain in pathologic states (Seal et al., 2009).

Conduction Velocity and Peak Frequency. We observed similar average conduction velocities for all three categories of skin C-fibers. The itch fibers averaged $0.55 \pm$ $0.03 \mathrm{~m} \cdot \mathrm{s}^{-1}(n=24)$, nociceptive fibers averaged $0.58 \pm$ $0.01 \mathrm{~m} . \mathrm{s}^{-1}(n=58)$, and C-LTMs averaged $0.64 \pm 0.04 \mathrm{~m} \cdot \mathrm{s}^{-1}$ $(n=11)$ (Fig. 2C). In terms of peak frequency induced by mechanical probing of the skin, the itch C-fibers fired with the peak frequency of $12.8 \pm 0.6 \mathrm{~Hz}(n=24)$, which was modestly but significantly less than the nociceptive C-fibers (15.7 \pm $0.6 \mathrm{~Hz}, n=58)$ or C-LTMs $(20.9 \pm 1.2 \mathrm{~Hz}, n=19)$ (Fig. 2D).

Expression of Voltage-Gated Sodium Channels. Using retrograde labeling and single-cell RT-PCR we evaluated the expression of $\alpha$-subunits of neuronal $\mathrm{Na}_{\mathrm{V}} 1$ channels in 74 skin-specific DRG neurons. To discriminate between $\mathrm{CQ}^{+}$ itch C-fiber neurons and nociceptive neurons, we considered the expression of MRGPRA3 mRNA as a marker of itch fiber neurons and the expression of TRPV1 but not MRGPRA3 mRNA as a marker of nociceptors (Liu et al., 2009).

C-LTMs were found to be capsaicin-negative so we also included in Fig. 4 data from non-TRPV1 expressing neurons. Unfortunately, we did not find a reliable marker for C-LTMs, so the TRPV1-negative neurons likely comprise C-LTM neurons as well as other TRPV1-negative neurons including non-nociceptive A-fiber neurons.

Of 74 evaluated neurons $24 \%$ were MRGPRA3 positive. This corresponds quantitatively with the $\mathrm{CQ}$-sensitive population of fibers discussed earlier. As expected, the percentage of MRGPRA3 expressing neurons that innervate the skin was 


\section{Nociceptors}

TRPV1+/MRGPRA3-

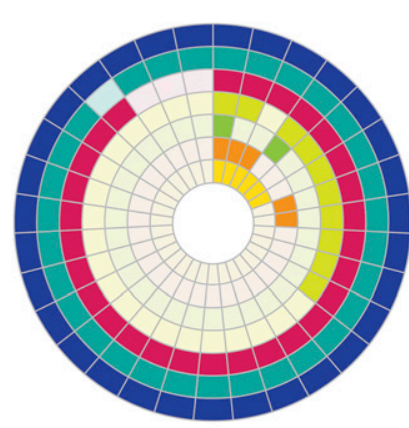

Itch fibers

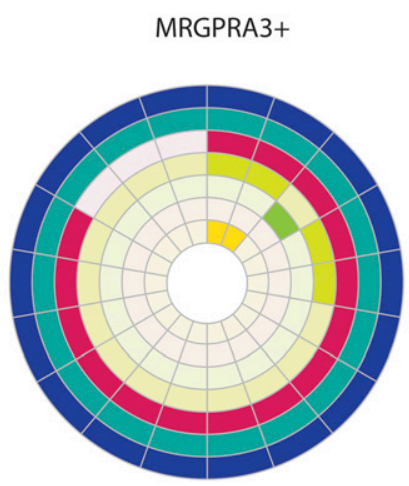

TRPV1-/MRGPRA3-

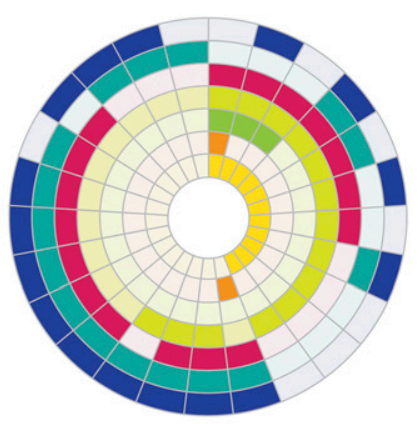

$\mathrm{NaV} 1.9$

$\mathrm{NaV} 1.7$

NaV1.6

$\mathrm{NaV} 1.3$

NaV1.2

NaV1.1

\begin{tabular}{lrrrrrrrr}
\hline & Nav1.1 & Nav1.2 & Nav1.3 & Nav1.6 & Nav1.7 & Nav1.8 & Nav1.9 & n-value \\
\cline { 2 - 8 } Nociceptors / TRPV1+, MRGPRA3- & $19.4 \%$ & $13.3 \%$ & $6.5 \%$ & $32.3 \%$ & $90.3 \%$ & $96.8 \%$ & $100.0 \%$ & 31 \\
\cline { 2 - 8 } Itch neurons / MRGPRA3+ & $11.1 \%$ & $0.0 \%$ & $5.9 \%$ & $22.2 \%$ & $83.3 \%$ & $100 \%$ & $100.0 \%$ & 18 \\
\hline TRPV1-, MRGPRA3- neurons & $44.0 \%$ & $8.0 \%$ & $12.0 \%$ & $56.0 \%$ & $68.0 \%$ & $64.0 \%$ & $64.0 \%$ & 25 \\
\hline
\end{tabular}

Fig. 4. Coexpression of sodium channels subtypes $\left(\mathrm{Na}_{v} 1 \mathrm{~s}\right)$ in dorsal root ganglia neurons innervating dorsal mouse skin. Top: Gene expression wheels. Each box represents a single neuron (depicted on the right). For each neuron the expression or lack thereof of seven Navs are shown by the filled in color (color coded on right); for instance, $\mathrm{Na}_{\mathrm{v}} 1.7$ expression is denoted as red in the third wheel. Note that all but three nociceptors and all but three itch fibers expressed Nav1.7. Neurons were divided based on the expression of nociceptor marker TRPV1 and chloroquine-receptor (MRGPRA3) into two subpopulations, presumably representing pain-evoking nociceptors (TRPV1 ${ }^{+}$and MRGPRA3 $^{-}$) and itch (scratch-evoking) C-fibers $\left(\mathrm{MRGPRA}^{+}\right.$). Virtually all these fibers express $\mathrm{Na}_{\mathrm{V}} 1.9$ and $\mathrm{Na}_{\mathrm{v}} 1.8$. This phenomenon was not observed in other (TRPV1 ${ }^{-}$and MRGPRA3 ${ }^{-}$) neurons that are included in the figure for comparison. Bottom: Relative expression of $\mathrm{Na}_{\mathrm{v}} \mathrm{s}$ transcripts in three identified subpopulations of dorsal root ganglia neurons.

much greater than the previously reported $\sim 5 \%$ of general DRG neuronal population (Liu et al., 2009).

The vast majority of the itch and nociceptive neurons expressed $\mathrm{Na}_{\mathrm{V}} 1.7,1.8$ and 1.9. In addition, about $30 \%$ of the nociceptive neurons expressed $\mathrm{Na}_{\mathrm{V}} 1.6$ and a smaller subpopulation of neurons expressed $\mathrm{Na}_{\mathrm{V}} 1.1,1.2$, and 1.3. About $20 \%$ of the MRGPRA3 itch neurons expressed $\mathrm{Na}_{\mathrm{V}} 1.6$, with most of the other $\mathrm{Na}_{\mathrm{V}} 1 \mathrm{~s}$ rarely expressed. The TRPV1negative neurons were, as might be expected, more heterogeneous with the major distinction from the MRGPRA3 and TRPV1-positive populations being that a smaller percentage expressed $\mathrm{Na}_{\mathrm{V}} 1.8$ or $\mathrm{Na}_{\mathrm{V}} 1.9$, and a larger percentage expressing $\mathrm{Na}_{\mathrm{V}} 1.1$ (Fig. 4).

Pharmacologic Blocking of Voltage-Gated Sodium Channels in the Skin. We evaluated the effect of $\mathrm{Na}_{V} 1$ blocking drugs added intra-arterially to the receptive field of cutaneous primary afferent nerve fibers on the action potential discharge in response to mechanical stimulation. We used concentrations of inhibitors expected to cause near complete blockade of the respective channels, based on our previous study with mouse isolated airway tissue (Kocmalova et al., 2017).

Tetrodotoxin Sensitivity. TTX $(1 \mu \mathrm{M})$ abolished action potential discharge in all C-LTMs $(n=8)$ and all nociceptors $(n=65)$. In contrast 4 of 19 of itch C-fibers responded normally when TTX-sensitive channels were blocked $(n=19)$ (Fig. 5).

TTX-Sensitive Channel Subtypes Involved in Action Potential Discharge. We used two selective $\mathrm{Na}_{\mathrm{V}} 1.7$ blockersPF-05089771 ( $3 \mu \mathrm{M}, n=36$ ) and compound 13 (3 $\mu \mathrm{M}, n=40)$; the results were similar for both, so we pooled the data. The selectivity of compound 13 is reported in Kocmalova et al. (2017), and the selectivity of PF-05089771 is reported in Alexandrou et al. (2016). We also evaluated PF-05089771 in our previously described $\mathrm{Na}_{v} 1.7$ assay using neuronally evoked cholinergic contractions of mouse trachea. We found that, as with compound 13 , the $\mathrm{IC}_{50}$ of this state-dependent inhibitor was $\sim 300 \mathrm{nM}$ (about 10-fold less potent than TTX), with maximal block occurring at 3-10 $\mu \mathrm{M}$.

It was recently reported that PF-05089771 can inhibit the TTX-resistant $\mathrm{Na}_{\mathrm{V}} 1.8$ current in human isolated DRG neurons (Zhang et al., 2017), so we have examined the effects of PF-05089771 on TTX-sensitive and TTX-resistant sodium current $\left(\mathrm{I}_{\mathrm{Na}}\right)$ in voltage-clamped isolated mouse $\mathrm{DRG}$ neurons. In three experiments, bath perfusion of PF-05089771 (3 $\mu \mathrm{M})$ for 5 minutes blocked the TTX-sensitive $\mathrm{I}_{\mathrm{Na}}$ by $54 \%, 85 \%$, and $92 \%$. In two of the three neurons where there was a notable TTX-resistant $\mathrm{Na}_{\mathrm{V}} 1.8$-like $\mathrm{I}_{\mathrm{Na}}$, PF-05089771 had essentially no inhibitory effect; at $-20 \mathrm{mV}$ there was 655 and $350 \mathrm{pA}$ in the absence of drug and 631 and $351 \mathrm{pA}$ in the presence of drug, respectively.

The Nav1.7 blockers abolished the responses of $64 \%$ of the nociceptive C-fibers $(n=42)$ and $42 \%$ of the itch C-fibers $(n=19)$, but only $18 \%$ of C-LTMs $(n=11)$ (Fig. 6$)$.

The $\mathrm{Na}_{\mathrm{v}} 1.1 / 1.2 / 1.3$ blocker ICA-121431 $(10 \mu \mathrm{M})$ alone had no effect on any C-fiber studied $(n=13)$. In four experiments where a C-LTM was not blocked by $\mathrm{Na}_{\mathrm{V}} 1.7$ blockers alone, they were each silenced by the further addition of ICA-121431. Among the eight nociceptive C-fibers that were not abolished by $\mathrm{Na}_{\mathrm{V}} 1.7$ blockers, adding ICA- 121431 abolished the response in four of the fibers. In contrast, further addition of ICA-121431 had no effect on $\mathrm{Na}_{\mathrm{V}} 1.7$ blocker-resistant itch C-fibers $(n=4)$. These data are tabulated in Table 2.

TTX-Insensitive Channel ( $\left.\mathrm{Na}_{\mathbf{v}} \mathbf{1 . 8}\right)$ Involved in Action Potential Discharge. The $\mathrm{Na}_{\mathrm{V}} 1.8$ blocker A803467 (30 $\left.\mu \mathrm{M}\right)$ alone had no effect on the activity of any C-fiber studied $(n=15)$. However, both itch and nociceptive C-fibers not 
A

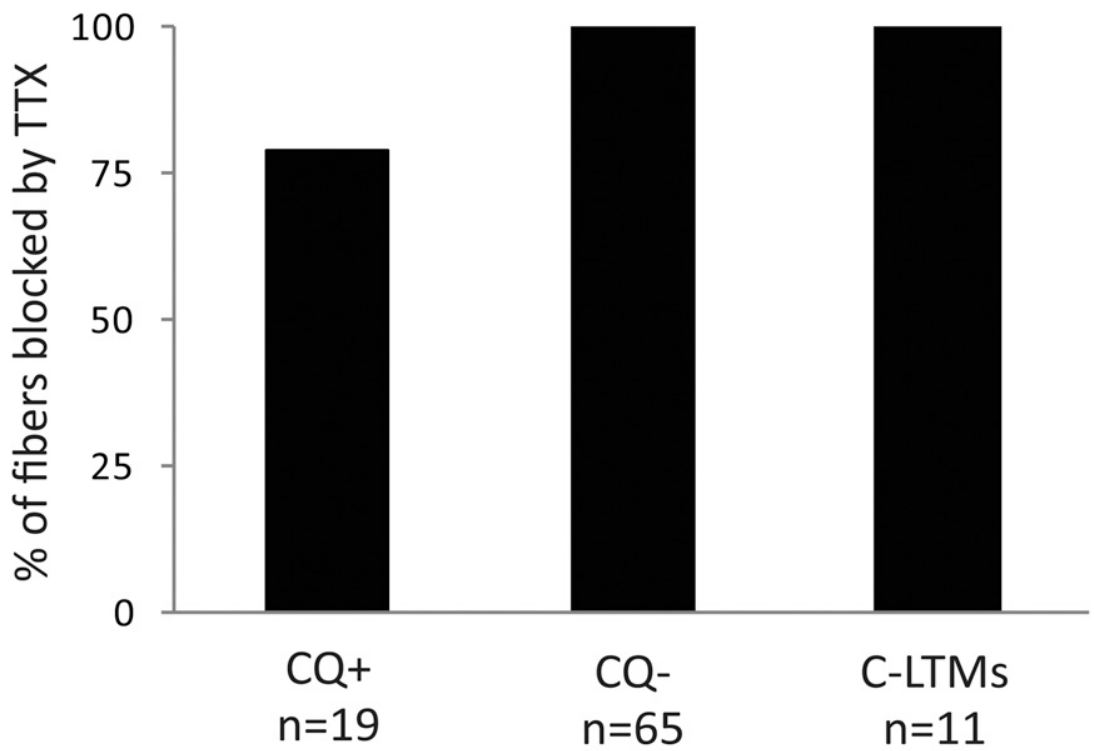

B
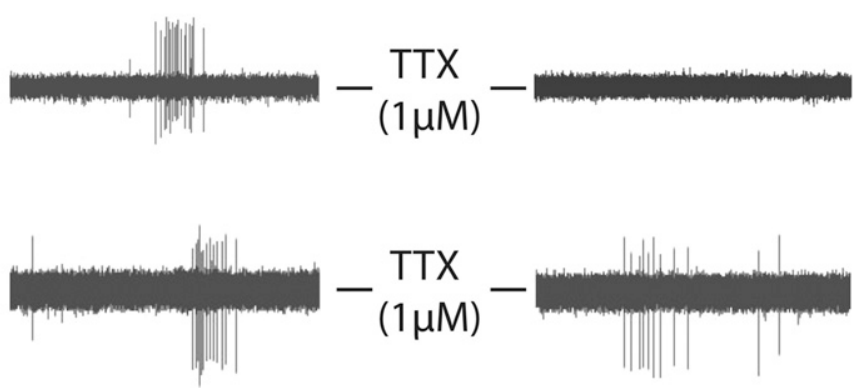

CQ- (nociceptor):

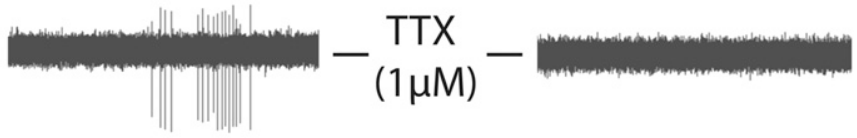

C-LTM:

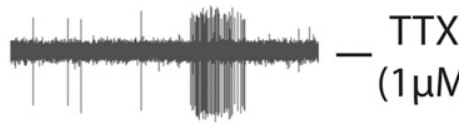

Fig. 5. Effect of tetrodotoxin (TTX) on C-fibers innervating the mouse skin. (A) Percentage of chloroquine-sensitive $\left(\mathrm{CQ}^{+}\right.$, itch fibers), $\mathrm{CQ}$-insensitive highmechanical-threshold C-fibers $\left(\mathrm{CQ}^{-}\right.$, nociceptors), and low-threshold mechanosensitive C-fibers (C-LTMs) blocked by TTX $(1 \mu \mathrm{M})$. (B) Representative traces of effect of TTX on CQ-sensitive (CQ+, itch fibers), CQ-insensitive high-mechanicalthreshold C-fibers ( $\mathrm{CQ}^{-}$, nociceptors), and low-threshold mechanosensitive C-fibers (C-LTMs) stimulated with von Frey hair, showing TTX-sensitive fibers and a TTXresistant itch fiber. For CQ-sensitive C-fibers $\left(\mathrm{CQ}^{+}\right.$, itch fibers), examples of a TTX-sensitive fiber and a TTX-resistant fiber are shown. silenced by $\mathrm{Na}_{\mathrm{V}} 1.7$ blockade were silenced by the further addition of A803467 (4 of 4 itch fibers, and 4 of 4 nociceptive fibers) (Table 2).

\section{Discussion}

The results indicate that within the cutaneous compartment of the C57BL/6J mouse dorsal thorax, selectively blocking $\mathrm{Na}_{\mathrm{V}} 1.7$ will silence AP discharge in about $40 \%-$ $60 \%$ of itch $\mathrm{C}$-fibers and nociceptive $\mathrm{C}$-fibers, but only rarely will it silence C-LTMs. A combination of a $\mathrm{Na}_{\mathrm{V}} 1.7$ and a 1.8 blocker would be predicted to block virtually all itch and nociceptive C-fibers and therefore eliminate pruritogenic or algogenic evoked C-fiber activation in this region of the skin. These therapeutic conclusions need to be tempered by the fact that the data were obtained from healthy skin and the activity and profile of $\mathrm{Na}_{\mathrm{V}}$ channels may change in disease (Dib-Hajj et al., 2010).
Using an ex vivo dorsal skin-nerve preparation we were able to characterize three nonoverlapping subsets of C-fibers in the skin of the dorsal thorax. All C-fibers were found by using a search paradigm where a small concentric electrode was used to probe the skin; all were mechanically sensitive to punctate stimulation with von Frey fibers. Based on the mechanical sensitivity, the anticipated two subpopulations of cutaneous C-fibers emerged: C-LTMs and C-HTMs, with the later far outnumbering the former.

The C-LTMs were unresponsive to all the chemical stimuli that we studied. Based on their chemical activation, we were able to distinguish between two subsets of C-HTM fibers. One subset was strongly activated by CQ $(24.2 \%)$ versus the larger subset that did not respond to $\mathrm{CQ}$. We previously noted that the majority of both of these subsets will respond to capsaicin, but the CQ-sensitive fibers selectively responded to three additional pruritic stimuli: cutaneous allergen challenge, histamine, and the MrgprC11 agonist BAM8-22 (Ru et al., 2017). 


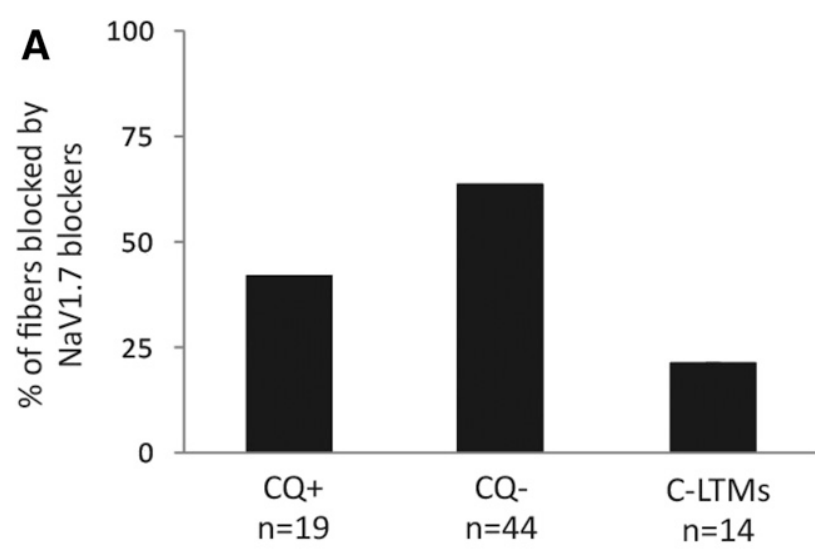

\section{B}

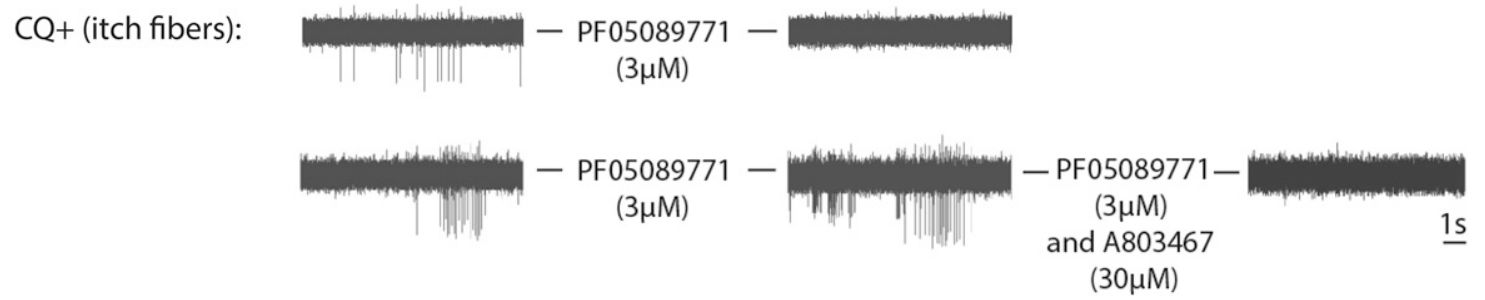

Fig. 6. Effect of $\mathrm{Na}_{\mathrm{v}} 1.7$-subtype selective blockers on C-fibers innervating the mouse skin. (A) Percentage of chloroquine-sensitive $\left(\mathrm{CQ}{ }^{+}\right.$, itch fibers), CQ-insensitive high-mechanical-threshold C-fibers ( $\mathrm{CQ}^{-}$, nociceptors), and low-threshold mechanosensitive C-fibers (C-LTMs) blocked by Nav1.7 blockers (pooled data for compound 13, $3 \mu \mathrm{M}$, and PF-05089771, $3 \mu \mathrm{M}$ ). (B) Representative traces of mechanical (von Frey) activation of CQ-sensitive $\left(\mathrm{CQ}^{+}\right.$, itch fiber) being silenced by the Nav1.7 blocker, and another $\mathrm{CQ}^{+}$fiber where blocking Nav1.7 had no effect but adding the Nav1.8 blocker $\mathrm{A} 803467$ silenced the fiber (A803467 alone does not inhibit the itch fibers). Note that after treatment with PF-05089771 another mechanically sensitive fiber appeared with a smaller amplitude - this fiber was also silenced by the addition of A803467.

Considering these data, along with the observation that selective deletion of CQ-sensitive neurons in the mouse DRG strongly reduced scratching to a variety of stimuli (Han et al., 2013), we ostensibly termed the CQ-sensitive nerves in the skin "itch C-fibers." That the pruritogen $(\mathrm{CQ}$, histamine, allergen, BAM8-22) insensitive $\mathrm{C}$-fibers, by contrast, responded strongly to algogenic chemicals (5-HT, $\alpha, \beta$-meATP, capsaicin), is the basis for referring to them as cutaneous nociceptive (likely pain evoking) C-fibers. The physiologic function of the C-LTMs in the dorsal skin remain ambiguous (Vallbo et al., 1999; Olausson et al., 2002; Löken et al., 2009; Seal et al., 2009). These three subsets of cutaneous C-fibers are likely a gross oversimplification, as it is reasonable to assume the two broad categories of C-HTMs would comprise phenotypical subsets should other stimuli be evaluated (see Dubin and Patapoutian, 2010).

Several previous studies in both laboratory animals and humans have observed mechanically silent $\mathrm{C}$-fibers in the skin (Kress et al., 1992; Weidner et al., 1999; Lawson et al., 2008). In ex vivo adult mouse skin-nerve preparations, akin to what was used here, Lawson et al. (2008) noted that about $10 \%$ of the cutaneous $\mathrm{C}$-fibers were mechanically insensitive. This study, however, focused mainly on the skin of the hind paw. The search paradigm was different between the two studies as well. In the present study, we only evaluated C-fibers in which the receptive field in the skin was first identified with a small,

TABLE 2

Effect of sodium channel blocking on C-fibers innervating the mouse skin

\begin{tabular}{lccc}
\hline & Itch Fibers $^{b}$ & Nociceptors $^{c}$ & C-LTMs $^{d}$ \\
\hline \% of C-fibers blocked & \\
TTX & & & \\
Nav1.7 blockers & & & \\
ICA-121431 & $78.9 \%(19)^{e}$ & $100 \%(65)$ & $100 \%(8)$ \\
A803467 & $42.1 \%(19)$ & $63.6 \%(44)$ & $21.4 \%(14)$ \\
$\%$ of Nav1.7 blocker-resistant fibers & $0 \%(4)$ & $0 \%(5)$ & $0 \%(4)$ \\
Nav1.7 blockers plus ICA-121431 & $0 \%(4)$ & $0 \%(7)$ & $0 \%(4)$ \\
Nav1.7 blockers plus A803467 & $0 \%(4)$ & $50 \%(8)$ & $100 \%(4)$ \\
\hline
\end{tabular}

${ }^{a}$ Mechanical response to punctuate stimulation with von Frey hairs was evaluated before and after incubation with $\mathrm{Na}_{\mathrm{V}}$ blockers. Fiber was considered to be blocked if it was unable to fire action potentials after applying adequate mechanical and chemical stimulus.

${ }^{b}$ Itch fibers are defined as high-mechanical-threshold chloroquine-sensitive C-fibers.

${ }^{c}$ Nociceptors are defined as high-mechanical-threshold chloroquine-insensitive C-fibers.

${ }^{d}$ Low-mechanical-threshold C-fibers.

e Total number of experiments.

${ }^{f}$ Pooled data for Na 1.7 blockers PF-05089771 (3 $\left.\mu \mathrm{M}\right)$ and compound $13(3 \mu \mathrm{M})$. 
concentric, stimulating electrode applied locally to the skin. In any event, it can be concluded that the vast majority of cutaneous $\mathrm{C}$-fibers in mouse skin are mechanically sensitive.

The single-cell RT-PCR analysis revealed that neurons with a presumed nociceptive phenotype (expressing TRPV1 but not MrgprA3) as well as those with a presumed itch phenotype (MrgprA3 expressing) express a similar profile of $\mathrm{Na}_{\mathrm{V}} 1 \alpha$ subunits genes, with $\mathrm{NaV} 1.7,1.8$, and 1.9 expressed most frequently. These data are in keeping with RNAseq analysis of MrgprA3-expressing DRG neurons where $\mathrm{Na}_{\mathrm{V}}$ 1.7, 1.8, and 1.9 were by far the dominate $\mathrm{Na}_{\mathrm{V}}$ subunits expressed (Usoskin et al., 2015).

Our analysis indicated that about $60 \%-70 \%$ of all neurons labeled from the dorsal region of mouse skin expressed TRPV1. This is a much larger percentage than observed in studies using immunohistochemistry to evaluate TRPV1 expression in mouse and rat cutaneous neurons (Tsukagoshi et al., 2006; Lawson et al., 2008). It is possible that the mRNA is not translated in all neurons, but the RT-PCR data are in keeping with our previous observation that the majority of C-fibers terminating in this region of the skin respond strongly with action potential discharge when capsaicin is applied to the cutaneous receptive field ( $\mathrm{Ru}$ et al., 2017).

It has previously been noted that the $\mathrm{Na}_{\mathrm{V}} 1$ subtypes supporting AP discharge may be different between the terminal region of the nerve within a tissue versus the conducting region of the axons in the extrinsic nerves (Brock et al., 1998; Kollarik et al., 2018). Therefore, by focusing on the effect of selective $\mathrm{Na}_{\mathrm{V}} 1$ blockers delivered intra-arterially to the receptive field in the isolated skin we were able to, for the first time, characterize the $\mathrm{Na}_{\mathrm{V}} 1$ subtypes supporting $\mathrm{AP}$ generation within the cutaneous tissue compartment. Although other studies indicate that TTX-resistant channels may be more dominant near and within the peripheral tissues than along the axons within the extrinsic nerves (Klein et al., 2017), it was notable that TTX selectively applied to the skin compartment was effective in silencing all C-LTMs as well as the vast majority of C-HTMs.

Selective $\mathrm{Na}_{\mathrm{V}} 1.7$ antagonism alone blocked the APs in only a minority $(\sim 40 \%)$ of skin itch C-fibers. Although the $\mathrm{Na}_{\mathrm{V}} 1.8$ blocker alone had no effect on itch C-fibers, in itch C-fibers that were not blocked by a $\mathrm{Na}_{\mathrm{V}} 1.7$ blocker adding the $\mathrm{Na}_{\mathrm{V}} 1.8$ blocker abolished the response. These data support the hypothesis that when drugs are limited to the cutaneous compartment, the combination of a $\mathrm{Na}_{V} 1.7$ and $\mathrm{Na}_{V} 1.8$ blockade will be more effective in inhibiting itch than blocking either channel alone.

A major role for $\mathrm{Na}_{\mathrm{V}} 1.7 \mathrm{in}$ itch has previously been inferred from in vivo studies where genetically deleting $\mathrm{Na}_{\mathrm{V}} 1.7$ virtually abolished scratching to histamine (Gingras et al., 2014). This was a greater inhibitory effect that would be predicted from the present study. This raises four possible explanations: first, that the drugs did not completely block $\mathrm{Na}_{\mathrm{V}} 1.7$ channels; second, that blocking some $40 \%$ of itch C-fibers is sufficient to inhibit all evoked scratching in the mouse; third, that deleting $\mathrm{Na}_{\mathrm{V}} 1.7$ led to the modulation of other relevant genes (e.g., see Minett et al., 2015); and fourth, that blocking $\mathrm{Na}_{\mathrm{V}} 1.7$ in extracutaneous aspects of the nerve is more effective in inhibiting AP conduction in itch C-fibers than what is observed within the skin. Sulfonamide-based Nav1.7 blockers (a class of $\mathrm{Na}_{\mathrm{V}} 1.7$ antagonists used also in our study) administered systemically before histamine intradermal injection reduced scratching by up to $85 \%$ (Graceffa et al., 2017; Kornecook et al., 2017; La et al., 2017).

A similar case can be made for cutaneous pain. The majority (65\%) of nociceptive C-fibers were silenced by the $\mathrm{Na}_{\mathrm{V}} 1.7$ blockers. In the remaining fibers blocking either $\mathrm{Na}_{\mathrm{V}} 1.8$ or other TTXsensitive $\mathrm{Na}_{\mathrm{V}} 1 \mathrm{~s}$ in addition to $\mathrm{Na}_{\mathrm{V}} 1.7$ silenced the nerves (none responded in presence of TTX). This was likely due to the presence of $\mathrm{Na}_{\mathrm{V}} 1.1 \mathrm{and} / \mathrm{or} 1.6$ in a subpopulation of these nerves. This observation is in general agreement with the findings of Kornecook et al. (2017), who noted that $\sim 50 \%$ of the TTXsensitive AP firing in the of tibial/saphenous nerves evoked by focal heat stimulation of the hind paw was blocked by an $\mathrm{Na}_{\mathrm{V}} 1.7$ blocker. Likewise, licking behavior evoked by intraplantar injection of capsaicin was inhibited by about $50 \%-75 \%$ with $\mathrm{Na}_{\mathrm{V}} 1.7$ blocking drugs (Graceffa et al., 2017; Kornecook et al., 2017).

The firmness of our conclusions depends on the selectivity of the $\mathrm{Na}_{\mathrm{V}} 1$ blockers studied. The selectivity can be challenged by the fact that large concentration of $\mathrm{Na}_{\mathrm{V}} 1$ blockers are required to abolish neural activation in isolated tissues relative to their potencies at inhibiting sodium currents under idealized patch clamp conditions. Data we obtained previously (and in the present study) with the mouse isolated trachea provides some insight about drug selectivity that is relevant to the present study (Kocmalova et al., 2017). The neuronallyevoked cholinergic contraction of the mouse trachea is dependent on a redundant role of $\mathrm{Na}_{V} 1.7, \mathrm{Na}_{\mathrm{V}} 1.1$, and $\mathrm{Na}_{\mathrm{V}} 1.3$ (Kocmalova et al., 2017). Accordingly, TTX abolishes the responses, as does the combination of a $\mathrm{Na}_{\mathrm{V}} 1.7$ blocker and ICA-121431 (to block $\mathrm{Na}_{\mathrm{V}} 1.1$ and 1.3). Alone, the $\mathrm{Na}_{\mathrm{V}} 1.7$ blockers used in the present study have no effect up to $10 \mu \mathrm{M}$ on the neuronal responses in the trachea, indicating their lack of effect on $\mathrm{Na}_{\mathrm{V}} 1.1$ and 1.3. Likewise, the $\mathrm{Na}_{\mathrm{V}} 1.1 / 1.2 / 1.3$ blocker ICA-121431 has no effect on neuronal tracheal contractions up to $10 \mu \mathrm{M}$, revealing its lack of effect of ICA-121431 on $\mathrm{Na}_{\mathrm{V}} 1.7$. When $\mathrm{Na}_{\mathrm{V}} 1.1$ and 1.3 were blocked with ICA-121431, compound 13 or PF-05089771 blocked the remaining $\mathrm{Na}_{\mathrm{V}} 1.7$ response with an $\mathrm{IC}_{50}$ of $\sim 300 \mathrm{nM}$ and complete blockade at 1-10 $\mu \mathrm{M}$. It must be kept in mind, however, that PF-05089771 will likely inhibit Nav1.6 in our tissue, and this channel was expressed in a small subset of pain and itch neurons.

With these caveats in mind, our data support the conclusion that the combination of topically applied $\mathrm{Na}_{\mathrm{V}} 1.7$ and $\mathrm{Na}_{\mathrm{V}} 1.8$ blockers would almost certainly reduce acute pain and itch emanating from the skin of the mouse.

\section{Acknowledgments}

We acknowledge the excellent technical assistance of Sonya Meeker.

\section{Authorship Contributions}

Participated in research design: Jurcakova, Ru, Kollarik, Sun, Krajewski, Undem.

Conducted experiments: Jurcakova, Ru, Sun.

Performed data analysis: Jurcakova, $\mathrm{Ru}$, Sun, Undem.

Wrote or contributed to the writing of the manuscript: Jurcakova, Kollarik, Undem.

\section{References}

Alexandrou AJ, Brown AR, Chapman ML, Estacion M, Turner J, Mis MA, Wilbrey A, Payne EC, Gutteridge A, Cox PJ, et al. (2016) Subtype-selective small molecule inhibitors reveal a fundamental role for $\mathrm{Na}_{\mathrm{v}} 1.7$ in nociceptor electrogenesis, axonal conduction and presynaptic release. PLoS One 11:e152405.

Brock JA, McLachlan EM, and Belmonte C (1998) Tetrodotoxin-resistant impulses in single nociceptor nerve terminals in guinea-pig cornea. J Physiol 512:211-217. 
Brozmanova M, Mazurova L, Ru F, Tatar M, Hu Y, Yu S, and Kollarik M (2016) Mechanisms of the adenosine A2A receptor-induced sensitization of esophageal C fibers. Am J Physiol Gastrointest Liver Physiol 310:G215-G223.

Dib-Hajj SD, Cummins TR, Black JA, and Waxman SG (2010) Sodium channels in normal and pathological pain. Annu Rev Neurosci 33:325-347.

Dubin AE and Patapoutian A (2010) Nociceptors: the sensors of the pain pathway. $J$ Clin Invest 120:3760-3772.

Emery EC, Luiz AP, Sikandar S, Magnúsdóttir R, Dong X, and Wood JN (2016) In vivo characterization of distinct modality-specific subsets of somatosensory neurons using GCaMP. Sci Adv 2:e1600990.

Gingras J, Smith S, Matson DJ, Johnson D, Nye K, Couture L, Feric E, Yin R, Moyer $\mathrm{BD}$, Peterson $\mathrm{ML}$, et al. (2014) Global $\mathrm{Na}_{\mathrm{v}} 1.7$ knockout mice recapitulate the phenotype of human congenital indifference to pain. PLoS One 9:e105895.

Graceffa RF, Boezio AA, Able J, Altmann S, Berry LM, Boezio C, Butler JR, ChuMoyer M, Cooke M, DiMauro EF, et al. (2017) Sulfonamides as selective Nav1.7 inhibitors: optimizing potency, pharmacokinetics, and metabolic properties to obtain atropisomeric quinolinone (AM-0466) that affords robust in vivo activity. J Med Chem 60:5990-6017.

Han L, Ma C, Liu Q, Weng HJ, Cui Y, Tang Z, Kim Y, Nie H, Qu L, Patel KN, et al. (2013) A subpopulation of nociceptors specifically linked to itch. Nat Neurosci 16 $174-182$.

Klein AH, Vyshnevska A, Hartke TV, De Col R, Mankowski JL, Turnquist B, Bosmans F, Reeh PW, Schmelz M, Carr RW, et al. (2017) Sodium channel $\mathrm{Na}_{\mathrm{v}} 1.8$ underlies TTX-resistant axonal action potential conduction in somatosensory C-fibers of distal cutaneous nerves. $J$ Neurosci 37:5204-5214.

Kocmalova M, Kollarik M, Canning BJ, Ru F, Adam Herbstsomer R, Meeker S, Fonquerna S, Aparici M, Miralpeix M, Chi XX, et al. (2017) Control of neurotransmission by NaV1.7 in human, Guinea pig, and mouse airway parasympathetic nerves. J Pharmacol Exp Ther 361:172-180.

Kollarik M, Sun H, Herbstsomer RA, Ru F, Kocmalova M, Meeker SN, and Undem BJ (2018) Different role of TTX-sensitive voltage-gated sodium channel (Nav1) subtypes in action potential initiation and conduction in vagal airway nociceptors. J Physiol 596:1419-1432.

Kornecook TJ, Yin R, Altmann S, Be X, Berry V, Ilch CP, Jarosh M, Johnson D, Lee JH, Lehto SG, et al. (2017) Pharmacologic characterization of AMG8379, a potent and selective small molecule sulfonamide antagonist of the voltage-gated sodium channel Nav1.7. J Pharmacol Exp Ther 362:146-160.

Kress M, Koltzenburg M, Reeh PW, and Handwerker HO (1992) Responsiveness and functional attributes of electrically localized terminals of cutaneous C-fibers in vivo and in vitro. $J$ Neurophysiol 68:581-595.

Kwong K, Carr MJ, Gibbard A, Savage TJ, Singh K, Jing J, Meeker S, and Undem BJ (2008) Voltage-gated sodium channels in nociceptive versus non-nociceptive nodose vagal sensory neurons innervating guinea pig lungs. J Physiol 586:1321-1336.

La DS, Peterson EA, Bode C, Boezio AA, Bregman H, Chu-Moyer MY, Coats J, DiMauro EF, Dineen TA, Du B, et al. (2017) The discovery of benzoxazine sulfonamide inhibitors of Nav1.7: tools that bridge efficacy and target engagement. Bioorg Med Chem Lett 27:3477-3485.

Lai J, Porreca F, Hunter JC, and Gold MS (2004) Voltage-gated sodium channels and hyperalgesia. Annu Rev Pharmacol Toxicol 44:371-397.

Lawson JJ, McIlwrath SL, Woodbury CJ, Davis BM, and Koerber HR (2008) TRPV1 unlike TRPV2 is restricted to a subset of mechanically insensitive cutaneous nociceptors responding to heat. J Pain 9:298-308.
Liu Q, Tang Z, Surdenikova L, Kim S, Patel KN, Kim A, Ru F, Guan Y, Weng HJ, Geng Y, et al. (2009) Sensory neuron-specific GPCR Mrgprs are itch receptors mediating chloroquine-induced pruritus. Cell 139:1353-1365.

Löken LS, Wessberg J, Morrison I, McGlone F, and Olausson H (2009) Coding of pleasant touch by unmyelinated afferents in humans. Nat Neurosci 12:547-548.

Markworth CJ, Marron BE, Rawson DJ, Storer RI, Swain NA, West CW, and Zhou S (2011) inventors, Icagen, Inc., and Pfizer Ltd., assignees. Chemical compounds. WIPO patent WO2012004706 A2. 2011 Jun 28.

Minett MS, Pereira V, Sikandar S, Matsuyama A, Lolignier S, Kanellopoulos AH Mancini F, Iannetti GD, Bogdanov YD, Santana-Varela S, et al. (2015) Endogenous opioids contribute to insensitivity to pain in humans and mice lacking sodium channel $\mathrm{Na}_{\mathrm{v}}$ 1.7. Nat Commun 6:8967.

Muroi Y, Ru F, Kollarik M, Canning BJ, Hughes SA, Walsh S, Sigg M, Carr MJ, and Undem BJ (2011) Selective silencing of Nav1.7 decreases excitability and conduction in vagal sensory neurons. J Physiol 589:5663-5676.

Olausson H, Lamarre Y, Backlund H, Morin C, Wallin BG, Starck G, Ekholm S, Strigo I, Worsley K, Vallbo AB, et al. (2002) Unmyelinated tactile afferents signal touch and project to insular cortex. Nat Neurosci 5:900-904.

Rozen S and Skaletsky H (2000) Primer3 on the WWW for general users and for biologist programmers. Methods Mol Biol 132:365-386.

Ru F, Sun H, Jurcakova D, Herbstsomer RA, Meixong J, Dong X, and Undem BJ (2017) Mechanisms of pruritogen-induced activation of itch nerves in isolated mouse skin. J Physiol 595:3651-3666.

Ru F, Surdenikova L, Brozmanova M, and Kollarik M (2011) Adenosine-induced activation of esophageal nociceptors. Am J Physiol Gastrointest Liver Physiol 300:G485-G493.

Seal RP, Wang X, Guan Y, Raja SN, Woodbury CJ, Basbaum AI, and Edwards RH (2009) Injury-induced mechanical hypersensitivity requires C-low threshold mechanoreceptors. Nature 462:651-655.

Surdenikova L, Ru F, Nassenstein C, Tatar M, and Kollarik M (2012) The neural crest- and placodes-derived afferent innervation of the mouse esophagus. Neurogastroenterol Motil 24:e517-e525.

Tsukagoshi M, Goris RC, and Funakoshi K (2006) Differential distribution of vanilloid receptors in the primary sensory neurons projecting to the dorsal skin and muscles. Histochem Cell Biol 126:343-352.

Usoskin D, Furlan A, Islam S, Abdo H, Lönnerberg P, Lou D, Hjerling-Leffler J, Haeggström J, Kharchenko O, Kharchenko PV, et al. (2015) Unbiased classification of sensory neuron types by large-scale single-cell RNA sequencing. Nat Neurosci 18:145-153.

Vallbo AB, Olausson H, and Wessberg J (1999) Unmyelinated afferents constitute a second system coding tactile stimuli of the human hairy skin. J Neurophysiol 81:2753-2763.

Weidner C, Schmelz M, Schmidt R, Hansson B, Handwerker HO, and Torebjörk HE (1999) Functional attributes discriminating mechano-insensitive and mechanoresponsive C nociceptors in human skin. J Neurosci 19:10184-10190.

Weigand LA, Myers AC, Meeker S, and Undem BJ (2009) Mast cell-cholinergic nerve interaction in mouse airways. J Physiol 587:3355-3362.

Zhang X, Priest BT, Belfer I, and Gold MS (2017) Voltage-gated $\mathrm{Na}^{+}$currents in human dorsal root ganglion neurons. eLife 6:e23235.

Address correspondence to: Dr. Bradley J. Undem, Department of Medicine, Johns Hopkins University School of Medicine, 5501 Hopkins Bayview Circle, Baltimore, MD 21224. E-mail: bundem@jhmi.edu 